\title{
The Effect of Job Stress and Psychological Burnout on Child- care Teachers' Turnover Intention: A Moderated Mediation Model of Gratitude
}

Introduction. Child-care teachers' turnover intention is very high in Korea because of low wage and hard work which cause job stress and psychological burnout. There is need for research to reduce turnover intention using psychological variables such as gratitude. Our purpose in this study was to verify when gratitude affects the mediating effects of psychological exhaustion in the link between job stress and turnover intention of 234 childcare teachers in Korea.

Study participants and methods. The participants in this study were 234 child-care teachers from Korea. Among the participants, $78.6 \%$ were married and $21.4 \%$ were single. The most common age group was 40 s with $49.1 \%$, 30s with $23.6 \%$, 20s with $15.0 \%$, and 50 s with 12.3\%. For analysis, we used SPSS Win.25.0 and PROCESS macro for SPSS 3.5 programs to do descriptive statistics analysis, reliability analysis, correlation analysis, and moderated mediation effect analysis.

Results. First, turnover intention had a positive correlation with job stress $(r=.506, p<.01)$ and psychological burnout $(r=.571, p<.01)$, and a negative association with gratitude $(r=-.339, p<.01)$. Second, conditional indirect effects of gratitude on the relationship between job stress and turnover intention through psychological burnout were significant $(p<.001)$ when the gratitude value was low $(M-1 S D)$, average $(M)$, or high $(M+1 S D)$. Therefore, the moderated mediation effect of gratitude was verified.

Practical significance. This study found out that gratitude of childcare teachers alleviates their turnover intention. This result will be used as a model to reduce the degree of turnover intention by using the gratitude of child-care teachers.

Keywords: job stress, psychological burnout, gratitude, turnover intention, moderated mediation

\section{For Reference:}

Hwang, Y. K., \& Lee, Ch. S. (2021). The Effect of Job Stress and Psychological Burnout on Childcare Teachers' Turnover Intention: A Moderated Mediation Model of Gratitude. Perspektivy nauki $i$ obrazovania - Perspectives of Science and Education, 49 (1), 390-403. doi: 10.32744/pse.2021.1.26 


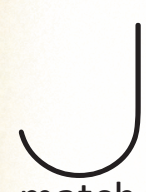

ob stress seems to be an inevitable shadow for office workers, who are subject to various demands and restrictions in the process of performing their duties as members of an organization, but when their abilities or circumstances do not match the job, they experience large and small job stresses. Job stress is a representative cause of job attitude and organizational performance, and even though it has been studied for a long time, it is constantly being studied in various academic fields, perhaps because of the seriousness of job stress. Those who experience job stress have a negative effect on organizational efficiency, because their motivation for work is reduced [1], and they also have less job satisfaction and organizational commitment and work poorly [2]. If job stress is not properly managed, it can cause problems not only at the individual level but also at the organizational level, so it is impossible to neglect job stress in academia or in the field.

In particular, job stress is closely related to turnover intention, which is the desire to voluntarily leave the organization to which they belong. When the intention to resign is increased, the concentration and enthusiasm for the job decrease, and thus the job efficiency decreases. In the event of a turnover, the turnover rate is also very important for organizational management, because the organization has to invest time and effort in hiring new manpower again to increase work skills. Also, organizations with a high turnover rate have serious problems, and there is no guarantee that they will not fall into the same problems again, even if there are other employees who can replace those who resign. Therefore, it is very important to understand the cause of the intention to resign and the specific process that occurs.

In this context, the relationship between job stress and turnover intention has been sufficiently verified for various occupations. In recent years, research has been expanded to clarify the process and principle of how job stress raises the intention to resign. The variable to note in the relationship between these two variables is psychological exhaustion, which is a phenomenon of exhaustion due to accumulated work stress for a long time [3]. This causes personal psychological and physical problems, such as helplessness, depression, decreased self-esteem, sleep problems, and forgetfulness [4].

Related studies show that job stress has an influence on psychological burnout [5; 6], and psychological burnout is a predictor of turnover intention [7]. Therefore, it is possible to infer to some extent that job stress can affect turnover intention through psychological exhaustion. However, the search for protective factors that can play an alternative role in this process is urgent. In other words, in the process of performing a job, everyone will experience stress, but this does not mean that all of them will increase their intention to resign, and it is predicted that there will be an invisible role of psychological variables. Therefore, in this study, we set gratitude, a representative variable of positive psychology, as a moderated mediation variable. People with strong appreciation tend to cope with stressful situations more actively and interpret them positively [7]. Therefore, even if persons with strong gratitude experiences job stress, the way they cope with job stress and the results of their actions may differ depending on the degree of gratitude.

In addition, job stress, psychological burnout, and job resignation are all variables that play a negative role. The input of gratitude, which focuses on the positive aspects of humans 
in such a negative environment, suggests that gratitude can act as a mechanism to slow down the negative path leading to job stress and to turnover intention.

Until now, research on job stress, psychological exhaustion, and job resignation has been partially underway, but there is no research to understand the role of gratitude, a key variable in positive psychology, beyond the scope of organizational behavioral variables. We need active research that can reduce negative consequences even if employees experience job stress, not just research at the level of grasping relationships. In particular, child-care teachers experience moderate stress due to heavy workloads and low wages in a job with a high resignation rate and are prone to psychological burnout. For this reason, we selected nursery teachers as the subject of this study.

Therefore, in this study we aimed to verify the moderated mediation effect of gratitude on the effects of job stress. Given the results, we hope to provide a model using gratitude as an alternative for reducing child-care teachers' intention to resign. To achieve this purpose, we set up the following research questions.

First, what are the correlations between job stress, psychological burnout, turnover intention, and gratitude?

Second, does psychological burnout mediate the link between job stress and turnover intention?

Third, does gratitude moderate the relationship between psychological burnout and intention resign?

Fourth, does gratitude moderate the mediating effect of psychological burnout on the relationship between job stress and turnover intention?

\section{Theoretical Background}

\section{Relationship between job stress and turnover intention}

Turnover intention is a strong predictive variable that has a decisive influence on resignation [9] and refers to the psychological state in which resignation can occur. Since it is difficult to empirically study the job changer when the job change has already been executed, different variables related to job change are being studied with a focus on jobchange intention.

On the other hand, child-care teaching is regarded as a job with a high resignation rate. The issue of child-care teacher resignation, the most important human resource that determines the quality of childcare, is being taken seriously around the world. In 1990, $60 \%$ of all early-childhood teachers in Canada left their jobs [10], and more than $30 \%$ of early-childhood teachers in the United States turn over each year [11]. When one child-care teacher leaves a job, other teachers must be trained to fill the vacancy, and colleagues may be less motivated to work [12]. Infants and toddlers go through the process of adjusting to a new teacher again [13]. In addition, even if a job change has not occurred, if a child-care teacher intends to leave, the sensitivity to the needs of infants to be cared for is lowered and the interaction is highly likely to decrease [14]. Therefore, in order to improve the quality of child care, it is very important to study the variables related to the child-care teachers' turnover intention.

Variables influencing the intention to resign include exhaustion [15] and job satisfaction [16]. Among them, job stress [17] is a representative causal variable. Job stress is a concept that limited stress to the organizational level, on which research has been actively conducted 
since the 1970s. The concept of job stress differs according to the related field of scholars. Occupational stress is also used in combination, but job stress is most commonly used. Job stress is a harmful physical and emotional reaction that occurs when job requirements do not match the ability, resources, or desires of workers [18].

Teachers' job stress is the experience of negative emotions, such as anxiety, frustration, tension, anger, and depression caused by the school situation [19]. The job stress of a childcare teacher can be defined as the negative physical, psychological, and emotional health that the child-care teacher experiences while performing his or her job in the child-care field. The job stress of child-care teachers can negatively affect the institution or infants where they work [20; 21], so active management is required.

Looking at studies on turnover intention and job stress, job stress positively affects turnover intention [22; 23]; the higher the job stress, the higher the turnover intention [24]; and job stress induces job resignation in the end [25]. In addition, child-care teachers with high job stress had negative cognition, behavior, and psychological status, had a passive attitude toward infants, parents, and colleagues, and perceived low professionalism as a teacher [26]. In the end, job stress creates an unstable psychological state of child-care teachers, lowers job ability and sensitivity to infants, and consequently negatively affects the quality of child care [27].

Based on previous studies, in this study we set the job stress of child-care teachers as an independent variable and turnover intention as a dependent variable, and tried to understand the role of psychological burnout and gratitude in the link between the two.

\section{The mediating effect of psychological burnout}

Burnout is a state of physical, emotional, and mental exhaustion that results from constant and repetitive emotional pressures in the process of maintaining close relationships with people for a long time [28]. In particular, occupational workers, such as teachers, who interact directly with people for a long time are more likely to experience emotional exhaustion and burnout in response to chronic stress. This symptom is psychological exhaustion [3].

Psychological burnout was conceptualized by the psychiatrist Freudenberger [4], and then research began with specific occupational workers, such as doctors and nurses in psychiatric hospitals. He observed that those caring for addicted patients gradually became cool to the patients. Psychological exhaustion from these people was defined as a state of exhaustion and burnout due to failure when trying to acquire energy, strength, or resources. Psychological burnout research gradually expanded to target various professions with the development of a measuring tool [3].

Child-care teachers play roles with important responsibilities as teachers, but they receive lower wages and worse treatment than do teachers in elementary, middle, and high schools, and suffer from heavy workloads and stress from excessive expectations from parents [29]. These tasks reduce the enthusiasm and energy for the teaching profession and eventually act as a cause of psychological exhaustion. When a child-care teacher who supports the overall development of infants and toddlers experiences psychological burnout, it has a negative effect on infants, parents, and organizations, so it is necessary to pay attention to the field in terms of both academia and policy.

Psychological burnout is a response to anxiety, tension, and job stress [30]. This was found to be a decisive factor in the stress process related to the job and a factor predicting the resignation rate of office workers [7]. Related studies include self-elasticity [31] and social support [31-33], self-esteem [34], empowerment [35], and self-efficacy [33; 36] have 
been found to affect psychological burnout, which has a negative effect on job satisfaction [37; 38] and increases depression and turnover intention [39]. Therefore, psychological burnout is used in various ways as a cause and effect variable in occupations that provide interpersonal services.

Meanwhile, studies using psychological burnout as a mediator have also been increasing recently. In the link between job demand and turnover intention, psychological burnout had a mediating effect [40] and mediated the link between occupational self-efficacy and turnover intention [41]. In addition, psychological burnout mediated the link between the job environment of the child-care teacher and the intention to reign [42]. The mediating effect of psychological burnout was also verified in the link between job stress and job satisfaction of early-childhood teachers [26].

Although the job stress experienced by the child-care teacher may affect the intention to resign, we predicted that it will have an effect through psychological exhaustion in this process, so psychological exhaustion was set as a mediating variable.

\section{Moderating effect of gratitude}

Humans live by constantly interacting with others in social life. In this process, humans feel and express gratitude for the benefits or positive experiences they have been given. Gratia, derived from the Latin word, is a complex psychological state that includes emotions, cognition, personality, and attitude as a positive emotion needed to pursue a happy life [43] and one of the reactions when receiving benefits from others [44].

Although gratitude itself is an indicator of happiness [45], feeling and expressing gratitude is a virtue for a happy and prosperous life. In academia, positive psychologists have conducted systematic research along with theoretical discussions on appreciation, and it is gratitude that they have conceptualized. We considered gratitude to be a constant and stable emotional trait beyond the emotions that people experience. Research on gratitude has not been going for very long, but such research is being actively conducted in various academic fields, such as pedagogy, psychology, and counseling. Gratitude is defined as a generalized tendency to recognize the goodwill of others and respond with positive emotions to positive experiences or results acquired by oneself [43].

People with high gratitude try to find positive attributes in situations that are easy to interpret negatively and can reinterpret the situation in a direction that is favorable to them [46]. In addition, they not only experience fewer psychological problems, but also reevaluate them in stressful situations to find positive meaning and actively cope with them. Therefore, appreciation is a factor that causes the growth of individuals or organizations [47] and is a very important competency to be developed for office workers.

Gratitude is receiving attention in various academic fields because it is closely related to life satisfaction, happiness, hope, and well-being, which are variables related to positive human psychology [48]. People with high gratitude experience fewer psychological problems, such as depression and anxiety. In addition, it has been reported that people with high gratitude have more positive traits, such as optimism and friendship, and have high satisfaction and well-being for life [47].

Recently, studies using gratitude as a moderating variable have also begun to appear. Gratitude moderated the relationship between parenting stress and subjective well-being of mothers in infancy [49], relationship between authentic leadership and happiness [50], relationship between stress and happiness of nursing students [51], and relationships between adolescents' irrational beliefs and game addiction [52]. However, it is difficult to 
find a study on the moderating effect of gratitude for child-care teachers, and there are few studies specifically related to job stress, psychological burnout, and turnover intention. Since gratitude is a representative variable with positivity in positive psychology, it is a predictable that it acts as a factor of happiness or life satisfaction. However, considering that organizations are trying to prevent the loss of human resources, on which the success or failure of the organization depends, it is very important to approach gratitude at an organizational level rather than at an individual psychological level and to identify its role.

Therefore, in this study we aimed to identify whom and when gratitude will affect the mediating effect of psychological burnout in the link between job stress and turnover intention by integrating the existing research results and establishing a new model.

Research method

\section{Research Model}

This study follows the moderated mediation effect analysis procedure of model 14 of PROCESS macro ver.3.5. The model of the study is shown in Figure 1.

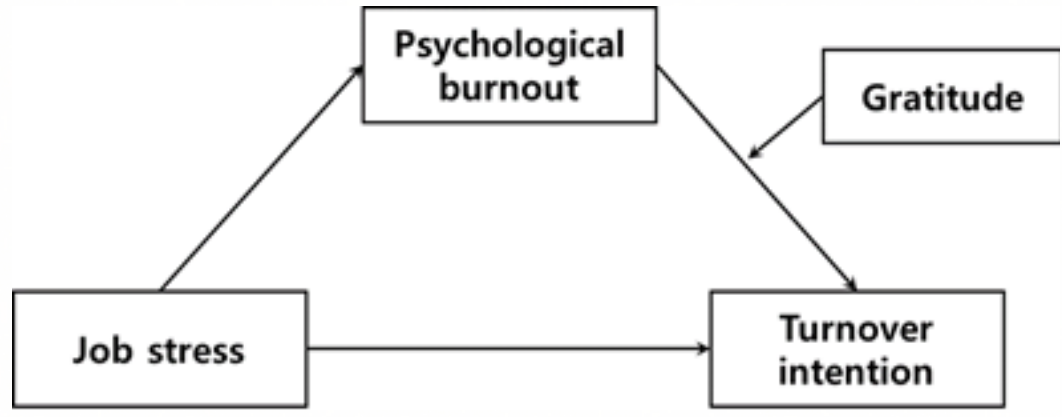

Figure 1 Conceptualized research model

\section{Participants and Data Collection Methods}

The participants in this study were 234 child-care teachers from Korea who were sampled purposively. We used a questionnaire to collect data. For the survey, we explained the purpose of the study and, after obtaining consent from the participants, conducted the survey from October to November 2019. Among the collected data, 234 copies were used for analysis, excluding faithless data. Among the participants, $78.6 \%$ were married and $21.4 \%$ were single. The most common age group was 40 s with $49.1 \%$, 30s with $23.6 \%$, 20 s with $15.0 \%$, and 50 s with $12.3 \%$.

\section{Research tools}

\subsection{Job stress}

We used the job-stress scale developed by Parker and Decotiis [2] and translated by An [53]. The sub-areas of this scale consist of psychological tension, job insecurity, and excessive work. Each question is on a 5-point Likert scale, with a total of 13 questions. The higher the score, the higher the job stress. In this study, the reliability by Cronbach's $\alpha$ was .877 .

\subsection{Psychological burnout}

We measured psychological burnout using a scale developed by Maslach and Jackson [3]. This scale is composed of three sub-areas, emotional exhaustion, dehumanization, and lack of achievement, with a total of 16 questions. Each question is on a 5-point Likert scale, 
and the higher the score, the higher the psychological burnout. In this study, Cronbach's $\alpha$ of psychological burnout was .904 .

\subsection{Turnover intention}

Turnover intention was measured using a scale developed by Mobley [54]. It has a total of 5 questions, each question is on a 5-point Likert scale, and the higher the score, the stronger the will to voluntarily leave the current job. In this study, the reliability of turnover intention by Cronbach's $\alpha$ was .877.

\subsection{Gratitude}

We assessed this variable using the Korean gratitude scale (K-GQ-6) which was validated by Kwon [47] using the Gratitude Questionnaire-6 (GQ-6) developed by McCullough et al. [43]. Originally, this scale used a 7-point Likert scale, but in this study, we used a 5-point Likert scale. The higher the score, the higher the gratitude, and the reliability of gratitude in this study was Cronbach's $\alpha=.845$.

\section{Data analysis}

We did descriptive statistics analysis, reliability analysis, and average comparison analysis using SPSS Win 25.0 and the PROCESS macro for the SPSS version 3.5 proposed by Hayes [55]. We did moderated mediating effect analysis by using the PROCESS macro, and used bootstrapping to verify this. The predictor and moderator variables were mean centered prior to computing the interaction product.

Results

\section{Correlations and Descriptive statistics}

We used Pearson's correlation analysis to find the correlations between variables; the results are shown in Table 1 . There was a statistically significant association between job stress, psychological burnout, gratitude, and turnover intention. Turnover intention had a positive correlation with job stress $(r=.506, p<.01)$ and psychological burnout $(r=.571$, $p<.01)$, and a negative association with gratitude $(r=-.339, p<.01)$. Job stress had a positive correlation with psychological burnout $(r=.730, p<.01)$ and a negative association with gratitude $(r=-.288, p<.01)$. There was a negative correlation between psychological burnout and gratitude $(r=-.364, p<.01)$. The highest average value among the variables was that of gratitude, with 4.0167 points, but none of job stress, psychological burnout, or job resignation exceeded the median value of 3 points.

Table 1

Correlations and descriptive statistics

\begin{tabular}{|l|c|c|c|c|c|c|}
\hline & Job stress & $\begin{array}{c}\text { Psychological } \\
\text { burnout }\end{array}$ & Gratitude & $\begin{array}{c}\text { Turnover } \\
\text { intention }\end{array}$ & M & SD \\
\hline Job stress & 1 & & & & 2.3537 & 0.73074 \\
\hline Psychological burnout & $.730^{* *}$ & 1 & & & 2.3516 & 0.59304 \\
\hline Gratitude & $-.288^{* *}$ & $-.364^{* *}$ & 1 & & 4.0167 & 0.60766 \\
\hline Turnover intention & $.506^{* *}$ & $.571^{* *}$ & $-.339^{* *}$ & 1 & 2.2560 & 0.88672 \\
\hline
\end{tabular}

${ }^{* *} p<.01$ 


\section{Moderated Mediation Effect}

In order to verify whether gratitude moderated the mediating effect of psychological burnout on the link between job stress and turnover intention, we applied the procedure of Model 14 of the PROCESS macro for SPSS proposed by Hayes [55]. The moderated mediation effect was verified using bootstrapping; at this time, we designated the number of samples as 5,000 and the confidence interval as $95 \%$. The analysis results are shown in Table 2 . In the link between job stress and turnover intention, the direct effect was not significant (.1002, $p>$.05). However, job stress increased psychological burnout, and psychological burnout significantly increased turnover intention, so psychological burnout played a mediating role in the link between job stress and turnover intention.

The interaction term between psychological burnout and gratitude had a significant effect on turnover intention, and the increase in $R^{2}\left(\Delta R^{2}=.0189, p<05\right)$ according to the interaction term was also significant; so gratitude moderated the relationship between psychological burnout and turnover intention.

The conditional effect of psychological burnout according to the gratitude value was significant $(p<.001)$ when the gratitude was low $(M-1 S D)$, average $(M)$, or high $(M+1 S D)$. As the gratitude value increased, the effect of psychological burnout decreased.

We used the Johnson-Neyman method, which is a floodlight, to analyze the conditional effect significance area of gratitude, a moderating variable. The conditional effect of psychological burnout was significant for all gratitude values. In other words, as the gratitude value increased, the conditional effect of psychological exhaustion decreased.

Conditional indirect effects (job stress $\rightarrow$ psychological burnout $\rightarrow$ turnover intention) on the relationship between job stress and turnover intention were significant $(p<.001)$ when the gratitude value was low (M-1 SD), average (M), or high ( $M+1 S D)$. When the gratitude value was increased, the conditional indirect effect decreased, and the moderated mediation effect index was also significant (-.3721 -.0639). Therefore, in the influence of job stress on turnover intention through psychological burnout, the moderated mediation effect of gratitude was verified.

Table 2

Analysis of the moderated mediation effect of gratitude on the relationship between job stress, psychological burnout, and turnover intention

\begin{tabular}{|c|c|c|c|c|c|c|}
\hline \multicolumn{7}{|c|}{ Mediating variable model (DV: Psychological burnout) } \\
\hline Variables & coeffect & se & 1. $t$ value & 2. $p$ & LLCI* & ULCI** \\
\hline Constant & -1.4243 & .0928 & -15.3464 & .0000 & -1.6072 & -1.2414 \\
\hline Job stress & 6101 & .0380 & 16.0403 & .0000 & .5352 & .6851 \\
\hline \multicolumn{7}{|c|}{ Dependent variable model (DV: Turnover intention) } \\
\hline Variables & $B$ & SE & 3. $t$ value & 4. $p$ & $\mathrm{LLCl}^{*}$ & $\mathrm{ULCI}^{* *}$ \\
\hline Constant & 1.9473 & .2263 & 8.6049 & .0000 & 1.5013 & 2.3933 \\
\hline Job stress & .1002 & .0956 & 1.0487 & .2955 & -.0881 & .2885 \\
\hline $\begin{array}{l}\text { Psychological } \\
\text { burnout }\end{array}$ & .7206 & .1208 & 5.9641 & .0000 & .4825 & .9588 \\
\hline Gratitude & -.1283 & .0828 & -1.5498 & .1226 & -.2915 & .0349 \\
\hline $\begin{array}{l}\text { psychological } \\
\text { burnout } \times \\
\text { gratitude }\end{array}$ & -.3553 & .1388 & -2.5601 & .0111 & -.6288 & -.0818 \\
\hline
\end{tabular}




\begin{tabular}{|c|c|c|c|c|c|c|}
\hline \multicolumn{7}{|c|}{ Test of highest order unconditional interaction } \\
\hline $\begin{array}{l}\text { 1. Interaction } \\
\text { term }\end{array}$ & \multicolumn{2}{|c|}{ 1. $R^{2}$} & \multicolumn{2}{|c|}{ 2. $F$} & \multicolumn{2}{|c|}{ 1. $p$} \\
\hline $\begin{array}{l}\text { Psychological } \\
\text { burnout x } \\
\text { Gratitude }\end{array}$ & \multicolumn{2}{|c|}{.0189} & \multicolumn{2}{|c|}{6.5543} & \multicolumn{2}{|c|}{.011} \\
\hline \multicolumn{7}{|c|}{ Conditional effects of psychological burnout according to gratitude values } \\
\hline Gratitude & Effect & se & $\mathrm{t}$ & $\mathrm{p}$ & LLCI* & ULCI** \\
\hline-.6043 & .9354 & .1617 & 5.7862 & .0000 & .6168 & 1.2539 \\
\hline .0000 & .7206 & .1208 & 5.9641 & .0000 & .4825 & .9588 \\
\hline .6043 & .5059 & .1309 & 3.8650 & .0001 & .2480 & .7639 \\
\hline \multicolumn{7}{|c|}{ Conditional effects of the psychological burnout at values of the gratitude } \\
\hline Gratitude & Effect & $\mathrm{F}$ & $\mathrm{t}$ & $\mathrm{p}$ & LLCI* & ULCI** \\
\hline-1.5311 & 1.2647 & .2668 & 4.7410 & .0000 & .7390 & 1.7904 \\
\hline-1.4061 & 1.2203 & .2513 & 4.8557 & .0000 & .7250 & 1.7155 \\
\hline \multicolumn{7}{|c|}{$\ldots$} \\
\hline .8439 & .4208 & .1484 & 2.8347 & .0050 & .1283 & .7133 \\
\hline .9689 & .3764 & .1596 & 2.3584 & .0192 & .0619 & .6909 \\
\hline \multicolumn{7}{|c|}{ Direct effect of Job stress on turnover intention } \\
\hline Effect & se & $\mathrm{t}$ & $\mathrm{p}$ & BootLLCI* & BootULCI** & \\
\hline .1002 & .0956 & 1.0487 & .2955 & -.0881 & .2885 & \\
\hline \multicolumn{7}{|c|}{$\begin{array}{l}\text { Conditional indirect effects of psychological burnout on turnover intention } \\
\text { (Job stress } \rightarrow \text { psychological burnout } \rightarrow \text { turnover intention) }\end{array}$} \\
\hline \multicolumn{3}{|c|}{ Gratitude } & Effect & BootSE & BootLLCI* & BootULCI** \\
\hline \multicolumn{3}{|c|}{-.6043} & .5707 & .0993 & .3811 & .7687 \\
\hline \multicolumn{3}{|c|}{.0000} & .4397 & .0811 & .2884 & .6063 \\
\hline \multicolumn{3}{|c|}{.6043} & .3087 & .0875 & .1403 & .4863 \\
\hline \multicolumn{7}{|c|}{ Index of moderated mediation } \\
\hline \multirow{2}{*}{\multicolumn{3}{|c|}{ Gratitude }} & Index & BootSE & BootLLCI* & BootULCI** \\
\hline & & & -.2168 & .0774 & -.3721 & -.0639 \\
\hline
\end{tabular}

${ }^{*} L L C I=$ The lower bound of the indirect effect within the 95\% confidence interval

$* * \mathrm{ULCl}=$ The upper bound of the indirect effect within the $95 \%$ confidence interval

The result of visualizing the conditional effect of psychological burnout by dividing gratitude into high, medium, and low is shown in Figure 3. In all three conditions of gratitude $(M \pm S D, M)$, turnover intention increased as psychological burnout increased and was directly proportional. Those with high gratitude showed a gentle slope, in which turnover intention increased with increasing psychological burnout, whereas those with low gratitude had a steeper slope, with increasing turnover intention as psychological burnout increased. In other words, the effect of psychological burnout on turnover intention depends on gratitude. That is, even when psychological burnout is high, people with high gratitude have less turnover intention than do those who are less grateful.

\section{Discussion and conclusion}

This study was conducted to understand the moderated mediating effect of gratitude on the effects of job stress and psychological burnout on Korean child-care teachers' turnover intention. The discussion based on the research results is as follows. 


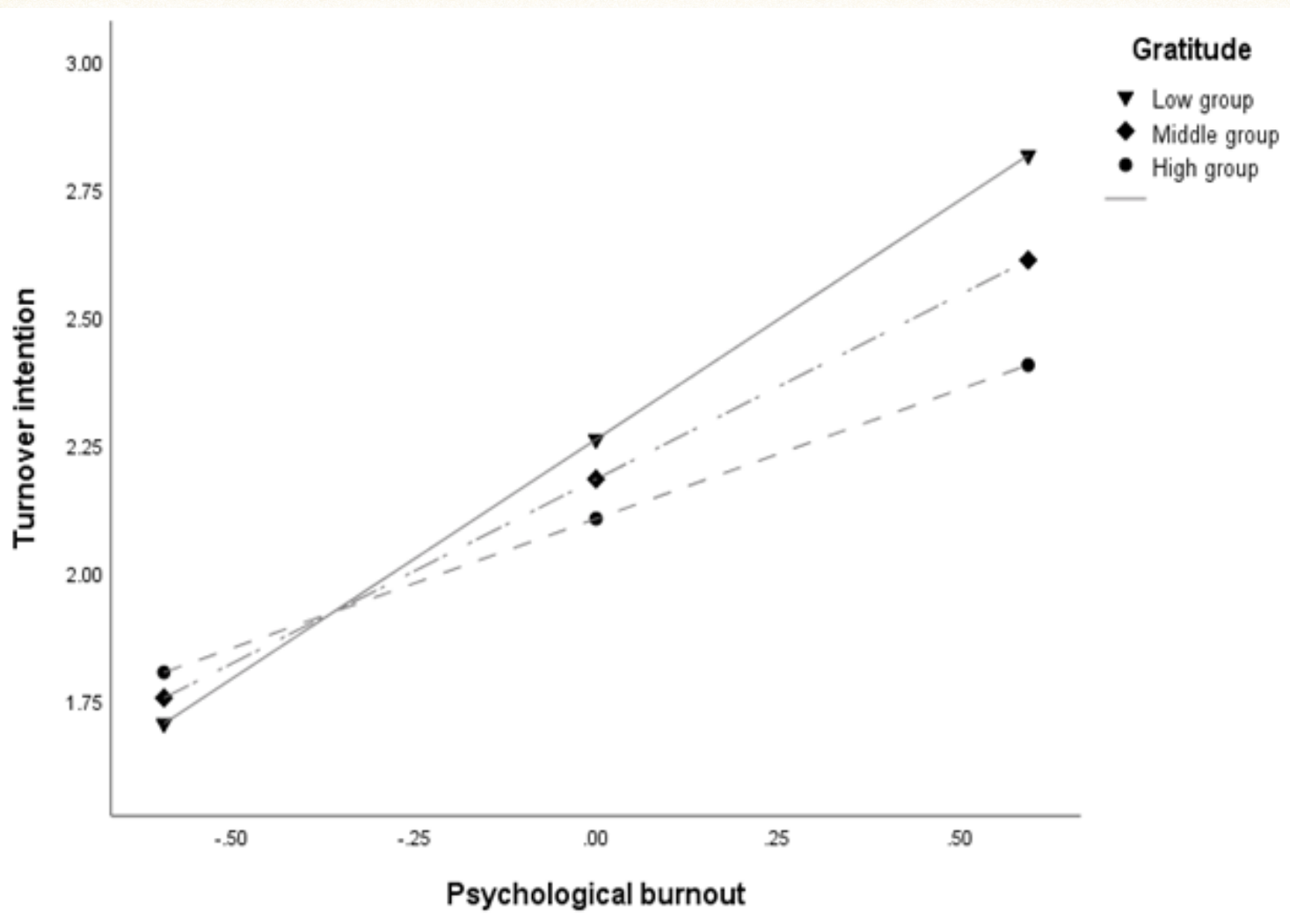

Figure 3 The moderating effect of gratitude on the mediating effect of psychological burnout

First, the Pearson correlation analysis showed that there were significant correlations between job stress, psychological burnout, gratitude, and turnover intention. Gratitude was negatively correlated with job stress, psychological burnout, and turnover intention, just as previous studies found that gratitude has a significant negative correlation with psychological burnout [56]; the more frequently job stress is experienced, the higher is the likelihood of psychological burnout [5], and the higher the job stress, the higher the turnover intention [24].

Second, psychological burnout had a mediating effect on the link between job stress and turnover intention. These results are in the same context as the research results that job stress had a direct effect on turnover intention [22; 23; 25], stress increased psychological burnout [5; 6], and psychological burnout influenced turnover intention [7]. Childcare teachers are subjected to job stress due to greater workloads and lower wages than other teachers receive, which creates a negative attitude toward their work. In addition, the sense of mission as a teacher and enthusiasm for the teaching profession in the early days were reduced, and even the high expectations and desires of parents were considered to be pressure, causing a psychological burnout, which eventually led to a job change. That is, the stress that a child-care teacher receives during job performance is an important cause of increasing turnover intention. In the end, the logic that job stress increases psychological burnout and eventually increases turnover intention was proved.

Third, gratitude moderated the relationship between psychological burnout and turnover intention. In other words, the psychological burnout experience increases the turnover intention, but in this process, the effect of psychological burnout depends on the degree of gratitude. People with high gratitude can find and reinterpret the positive side even in negative situations [57]. On the other hand, in a difficult situation where the sense 
of mission and passion as a teacher are exhausted, people with less gratitude have a higher turnover intention than do those who feel more grateful.

Fourth, the moderated mediation effect of gratitude was verified in the path of job stress and turnover intention through psychological burnout. In other words, the indirect effect of job stress on turnover intention via psychological burnout depends on gratitude, and as the degree of gratitude increases, the effect of psychological burnout on turnover intention gradually decreases. This means that even though people experience psychological burnout due to job stress, people with high gratitude have less turnover intention than do those who feel less grateful. In work life, anyone can experience psychological burnout due to large and small job stress, but not all of them decide to resign, and gratitude, a psychological variable, work as a mechanism by which job stress slows the negative path leading to turnover intention through psychological burnout.

This study analyzed the moderated mediation effect of gratitude on the effects of job stress and psychological burnout on turnover intention. This study is very meaningful in that this goes beyond the search for the relationship between the independent and dependent variables or the mediating variable, and in that a new variable that can reduce their mutual influence was derived, and the theoretical validity of each variable was verified to integrate the previous studies done individually.

Nevertheless, suggestions for further research are as follows. First, in this study, it was found that gratitude moderates the effect of job stress on child-care teachers' turnover intention via psychological burnout. Therefore, it is very urgent to develop and apply practical programs that can increase gratitude for child-care teachers.

Second, the resignation rate of child-care teachers is a very important matter that is directly related to the quality of education. However, most of the studies focus on identifying the causative variable that affects the resignation rate, so academic efforts to reduce the job stress are lacking. Of course, the role of psychological burnout and gratitude in this study was identified, but without a job environment that can reduce job stress, an increase in resignation and a decline in the quality of child care inevitably become a vicious cycle. Therefore, there is a need to improve treatment, policy support, and empirical research in the academic world at the same time, so that child-care teachers can take pride in their jobs.

\section{REFERENCES}

1. Ilgen, D. R. (1990). Health issues at work: Opportunities for industrial/organizational psychology. American Psychologist, 45(2), 273-283. https://doi.org/10.1037/0003-066X.45.2.273

2. Parker, D. F., \& DeCotiis, T. A. (1983). Organizational determinants of job stress. Organizational Behavior and Human Performance, 32(2), 160-177. https://doi.org/10.1016/0030-5073(83)90145-9

3. Maslach, C., \& Jackson, S. E. (1981). The measurement of experienced burnout. Journal of Organizational Behavior, 2(2), 99-113. https://doi.org/10.1002/job.4030020205

4. Freudenberger, H. J. (1974). Staff burn-out. Journal of Social Issues, 30(1), 159-165. https://doi. org/10.1111/j.1540-4560.1974.tb00706.x

5. Wilkerson, K. (2009). An examination of burnout among school counselors guided by stress-strain-coping theory. Journal of Counseling \& Development, 87(4), 428-437. https://doi.org/10.1002/j.1556-6678.2009.tb00127.x

6. Travers, C. J., \& Cooper, C. L. (1996). Teachers under pressure: Stress in the teaching profession. Psychology Press.

7. Van Maele, D., \& Van Houtte, M. (2014). Trust in the school principal: a pathway to inhibit teacher burnout in elementary education?. In Annual Conference of the American Educational Research Association. Retrieved from: http://hdl.handle.net/1854/LU-4384931

8. Wood, A. M., Joseph, S., \& Linley, P. A. (2007). Coping style as a psychological resource of grateful people. Journal of Social and Clinical Psychology, 26(9), 1076-1093. https://doi.org/10.1521/jscp.2007.26.9.1076

9. Mun, M. S. (2007). A Study on the Relations between Child-care teachers' Departure Intentions and Their Work 
Environment and Job Satisfaction (Masters' Thesis). The Graduate School of Education Duksung Women's University, Seoul, Korea. Retrieved from: http://www.riss.kr/link?id=T11051901

10. LaGrange, A., \& Read, M. (1990). Those who care: A report on child caregivers in alberta daycare centres. Retrieved from: https://eric.ed.gov/?id=ED329358

11. Gable, S., \& Hunting, M. (2001). Child care providers' organizational commitment: A test of the investment model. Child and Youth Care Forum, 30(5), 265-281. https://doi.org/10.1023/A:1014425310598

12. Suh, J. Y., \& Suh, Y. S. (2002). Influential factors on turnover intention of Korean kindergarten teachers. Korean Journal of Early Childhood Education, 22(4), 229-250. Retrieved from http://www.riss.kr/link?id=A99534587

13. Beak, Y. S. (2014). A study on moderating effects of personally.environmentally protective factors in the relationship between child care teachers' job stress and turnover intentions (Doctoral Dissertation). Graduate School of Sookmyung Women's University, Seoul, Korea. Retrieved from: http://www.riss.kr/link?id=T13368246

14. Howes, C., \& Hamilton, C. E. (1992). Children's relationships with child care teachers: Stability and concordance with parental attachments. Child Development, 63(4), 867-878. https://doi.org/10.1111/j.1467-8624.1992.tb01667.x

15. Yoo, H. S., \& Kwon, J. H. (2017). Structural relations among child care teachers` job stress, teacher efficacy, organizational commitment, burn-out and turnover intention. Early Childhood Education Research \& Review, 21(1), 113-132. Retrieved from: http://www.dbpia.co.kr/journal/articleDetail?nodeld=NODE07446097

16. Kang, J. H., \& Kim, J. Y. (2013). Relationships between family child care teacher's job satisfaction and turnover intention. The Korea Association of Child Care and Education, 76, 121-138. Retrieved from: http://www.riss.kr/ link?id=A99593176

17. Pyo, G. S., \& Hwang, Y. J. (2011). A study on the influence of job stress on turnover intentions of child care teachers in small and medium-sized cities: Moderating effects of leadership of directors. The Korea Association of Child Care and Education, 66, 1-23. Retrieved from: http://www.dbpia.co.kr/journal/articleDetail?nodeld=NODE01602466

18. NIOSH Working Group. (1999). Stress at work. Cincinnati: National Institute for Occupational Safety and Health (NIOSH).

19. Kyriacou, C., \& Sutcliffe, J. (1978). Teacher stress: Prevalence, sources, and symptoms. British Journal of Educational Psychology, 48(2), 159-167. https://doi.org/10.1111/j.2044-8279.1978.tb02381.x

20. Weisberg, J., \& Sagie, A. (1999). Teachers' physical, mental, and emotional burnout: Impact on intention to quit. The Journal of Psychology, 133(3), 333-339. https://doi.org/10.1080/00223989909599746

21. Schuler, R. S. (1980). Definition and conceptualization of stress in organizations. Organizational Behavior and Human Performance, 25(2), 184-215. https://doi.org/10.1016/0030-5073(80)90063-X

22. Kemery, E. R., Mossholder, K. W., \& Bedeian, A. G. (1987). Role stress, physical symptomatology, and turnover intentions: A causal analysis of three alternative specifications. Journal of Organizational Behavior, 8(1), 11-23. https://doi.org/10.1002/job.4030080103

23. Lee, H. B., \& Lee, S. C. (2006). A study on the relationship of job stress, job satisfaction, organizational commitment and turnover intention of policemen. Korean Review of Organizational Studies, 3(2), 83-101. Retrieved from: http:// www.dbpia.co.kr/journal/articleDetail?nodeld=NODE01099785

24. Mosadeghrad, A. M., Ferlie, E., \& Rosenberg, D. (2011). A study of relationship between job stress, quality of working life and turnover intention among hospital employees. Health Services Management Research, 24(4), 170181. https://doi.org/10.1258\%2Fhsmr.2011.011009

25. Stordeur, S., D'hoore, W., \& Vandenberghe, C. (2001). Leadership, organizational stress, and emotional exhaustion among hospital nursing staff. Journal of Advanced Nursing, 35(4), 533-542. https://doi.org/10.1046/j.13652648.2001.01885.x

26. Kwon, Y. R., \& Moon, Y. K. (2016). An analysis on meditating effect between the teacher efficacy and the job stress with regard to child care teacher's social support and turnover. Korean Journal of Child Education and Care, 16(1), 99-119. Retrieved from http://www.dbpia.co.kr/journal/articleDetail?nodeld=NODE07451174

27. Kim, B., \& Shin, H. Y. (2000). An exploratory study on job stress of day care teacher. Korean Journal of Early Childhood Education, 20(3), 253-276. Retrieved from http://kiss.kstudy.com/thesis/thesis-view.asp?key=1611706

28. Maslach, C., Jackson, S. E., Leiter, M. P., Schaufeli, W. B., \& Schwab, R. L. (1986). Maslach burnout inventory (Vol. 21, pp. 3463-3464). Palo Alto, CA: Consulting psychologists press.

29. Chae, Y. R. (2016). Effects of the job stress on the job satisfaction of preschool teacher: Focusing on mediation effects of burnout. Early Childhood Education Research \& Review, 20(4), 27-46. Retrieved from: http://www.dbpia. co.kr/journal/articleDetail?nodeld=NODE07446026

30. Cherniss, C., \& Cherniss, C. (1980). Staff burnout: Job stress in the human services (p. 21). Beverly Hills, CA: Sage publications.

31. Kim, N. Y., \& Jung, H. H. (2012). The effect of demographic variables on art therapist's psychological burnout and ego-resiliencey. Journal of Clinical Art Psychotherapy, 2(1), 43-58. Retrieved from: http://scholar.dkyobobook.co.kr/ searchDetail.laf?barcode $=4050026594751 \#$

32. Jo, S. H., Kang, D. O., \& Kim, S. C. (2018). The influence of educare teachers' self-encouragement and social support on psychological burnout. Korean Journal of Child Education and Care, 18(4), 51-63. Retrieved from: http://www. dbpia.co.kr/journal/articleDetail?nodeld=NODE07590829

33. Baek, S. K., Kim, S., Cheon, S. M., \& Ju, D. B. (2011). The influence of self-efficacy, emotional labor, and social support 
on job center workers' psychological burnout. The Journal of Vocational Education Research, 30(4), $129-141$. Retrieved from https://www.kci.go.kr/kciportal/ci/sereArticleSearch/ciSereArtiView.kci?sereArticleSearchBean. artild=ART001613819

34. Sul, J. S., \& Kim, S. Y. (2018). An exploratory study on the effect of corporate instructor's self-esteem on communication skills and psychological burnout. Korean Journal of Communication Studies, 26(2), 235-258. https:// doi.org/10.23875/kca.26.2.10

35. Seo, H. K. (2017). The effects of empowerment on teachers' psychological burnout. The Journal of Lifelong Education and $H R D, 13(3), 55-86$. Retrieved from https://www.earticle.net/Article/A326758

36. Kim, Y. M., \& Park, Y. S. (2008). The effects of music therapists' personality characteristics and self-efficacy on burnout. Korean Journal of Stress Research, 16(1), 13-20. Retrieved from http://www.dbpia.co.kr/journal/articleDe tail?nodeld=NODE02012815

37. Kwon, H. S., \& Kim, Y. Y. (2015). Influence of factors originated from demographic factors, personal characteristics and work-related factors on the intention for turnover of kindergarten teachers. Discourse and Policy in Social Science, 8(1), 55-75. Retrieved from http://www.dbpia.co.kr/journal/articleDetail?nodeld=NODE06285048

38. Kim, P. U. \& Cho, S. J. (2015). The effect on self-esteem according to job satisfaction and the psychological exhaustion of kindergarten teacher: With a Focus on T-Gu, Ulsan City. Journal of Korea Institute of Information, Electronics, and Communication Technology, 8(2), 169-177. Retrieved from: http://www.dbpia.co.kr/journal/articleDetail?nodeld= NODE06614724

39. Hong, G. H., \& Jung, H. J. (2013). Effect of preschool teacher's job stress and depression on burnout: Focusing on the moderating effect of depression. Journal of Korean Child Care and Education, 9(1), 263-280. Retrieved from: http:// www.riss.kr/link?id=A104443294

40. Choi, H. N., Son, J. Y., \& Lee, E. J. (2013). Relationships among job demand, burnout and turnover intentions of youth companion: The mediating effect of burnout. Korea Journal of Counseling, 14(1), 191-207. Retrieved from: http:// www.riss.kr/link?id=A100179535

41. Park, J. H., \& So, H. J. (2019). The mediated effects of burnout on the relationships between career self-efficacy and turnover intention of music therapists. Journal of Arts Psychothreapy, 15(4), 247-269. https://doi.org/10.32451/ KJOAPS.2019.15.4.247

42. Choi, H. J., Jung, J. H., \& Lee, H. R. (2020). The effects of childcare teacher's perceived job environment on turnover intention: Mediating effect of psychological exhaustion. The Journal of Korea Open Association for Early Childhood Education, 25(2), 157-175. https://doi.org/10.32451/KJOAPS.2019.15.4.247

43. McCullough, M. E., Emmons, R. A., \& Tsang, J. A. (2002). The grateful disposition: A conceptual and empirical topography. Journal of Personality and Social Psychology, 82(1), 112-127. https://doi.org/10.1037/00223514.82.1.112

44. McCullough, M. E., Kilpatrick, S. D., Emmons, R. A., \& Larson, D. B. (2001). Is gratitude a moral affect?. Psychological Bulletin, 127(2), 249-266. Retrieved from: https://psycnet.apa.org/buy/2001-16969-004

45. Watkins, P. C. (2004). Gratitude and Subjective Well-Being. In R. A. Emmons \& M. E. McCullough (Eds.), Series in affective science. The psychology of gratitude (p. 167-192). Oxford University Press. https://doi.org/10.1093/acpro f:oso/9780195150100.003.0009

46. Watkins, P., Scheer, J., Ovnicek, M., \& Kolts, R. (2006). The debt of gratitude: Dissociating gratitude and indebtedness. Cognition \& Emotion, 20(2), 217-241. https://doi.org/10.1080/02699930500172291

47. Kwon, S. J., Kim, K. H., \&, Lee, H. S. (2006). Validation of the Korean version of gratitude questionnaire. Korean Journal of Health Psychology, 11(1), 177-190. Retrieved from http://www.dbpia.co.kr/journal/articleDetail?nodeld $=$ NODE06368647

48. Watkins, P. C., Woodward, K., Stone, T., \& Kolts, R. L. (2003). Gratitude and happiness: Development of a measure of gratitude, and relationships with subjective well-being. Social Behavior and Personality: an international journal, 31(5), 431-451. https://doi.org/10.2224/sbp.2003.31.5.431

49. Choi, N. L., \& Jin, M. K. (2014). The moderating effects of gratitude on the relationship between parenting stress and the subjective well-being of mothers with young children. Korean Journal of Play Therapy, 17(4), 453-469. Retrieved from: http://kiss.kstudy.com/thesis/thesis-view.asp?key=3280207

50. Park, J. W., \& Oh, S. J. (2020). The influence of authentic leadership on happiness: An examination of the mediating effect of psychological empowerment and the moderating effect of grateful disposition. The Korean Leadership Review, 11(3), 95-121. https://doi.org/10.22243/tklq.2020.11.3.95

51. Kwon, Y. S. (2019). The moderating effect of gratitude disposition in the relationship between stress and happiness in nursing students. Journal of the Korea Convergence Society, 10(2), 105-112. https://doi.org/10.15207/ JKCS.2019.10.2.105

52. Jung, Y. H., Lee, M. Y., Im, S. H., Kwon, S. J., \& Cheon, S. M. (2014). The relationship between irrational beliefs and gaming addiction in adolescents: The moderating role of gratitude. Korean Journal of Educational Therapist, 6(1), 1-12. Retrieved from: http://www.riss.kr/link?id=A100294698

53. An, J. S. (1999). A study on the stress of service workers' emotional labor: Focusing on the hotel industry. (Masters' Thesis). Gyeonggi University. Seoul. Retrieved from: http://www.riss.kr/link?id=T8872322

54. Mobley, W. H. (1982). Employee turnover, causes, consequences, and control. Readings, MA: Addison-Wesley. 
55. Hayes, A. F. (2017). Introduction to mediation, moderation, and conditional process analysis: A regression-based approach. Guilford publications.

56. Kim, Y. W. (2016). Controlling effect of gratitude of disposition and perceiving a calling within the relationship between secondary school teachers' job stress and psychological burn out. (Masters' Thesis). Ewha Womans University. Seoul. Retrieved from: http://www.riss.kr/link?id=T13975968

57. Watkins, P., Scheer, J., Ovnicek, M., \& Kolts, R. (2006). The debt of gratitude: Dissociating gratitude and indebtedness. Cognition \& Emotion, 20(2), 217-241. https://doi.org/10.1080/02699930500172291

\section{Information about the authors}

Yeoun Kyoung Hwang

(South Korea, Seosan city)

Doctor of Lifelong Education, Professor for Academic Research

Multicultural Education and Welfare Institute, Hanseo University

E-mail: 01020707980@hanmail.net

ORCID ID: 0000-0002-4530-3641

\section{Chang Seek Lee}

(South Korea, Seosan city)

Doctor of Philosophy, Professor, Department of Health, Counseling and Welfare

Hanseo University

E-mail: lee1246@hanmailnet

ORCID ID: 0000-0002-9222-1953 